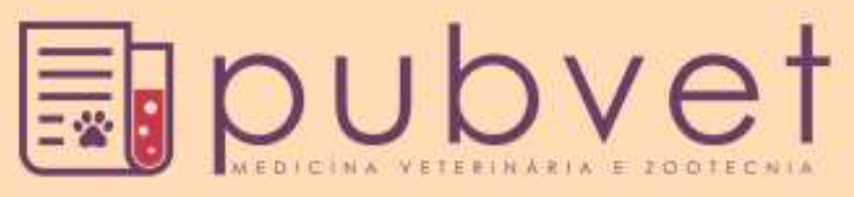

https://doi.org/10.22256/pubvet.v12n1a14.1-10

\title{
Síntese proteica em suínos: como fêmeas, machos não castrados e castrados respondem a este processo?
}

\author{
Alessandra Nardina Trícia Rigo Monteiro ${ }^{\infty} 1^{*}$, Laura Marcela Diaz Huepa ${ }^{\oplus} 1$, Leandro \\ Dalcin Castilha ${ }^{6}$, Paulo Cesar Pozza 2
}

${ }^{I}$ PhD em Zootecnia, Universidade Estadual de Maringá, PR-Brasil.

${ }^{2}$ Professores Universidade Estadual de Maringá. Departamento de Zootecnia, Maringá, PR-Brasil.

* Autor para correspondência a_monteiro@zootecnista.com.br

\begin{abstract}
RESUMO. A síntese proteica muscular em suínos é essencial para promover o ganho de carne marga. Entretanto, é um processo complexo que envolve inúmeras enzimas, proteínas ribossomais e pode ser influenciado por diversos fatores, de ordem ambiental, nutricional e hormonal. Neste sentido, os hormônios sexuais podem exercer ação anabólica na síntese proteica, levando a diferentes taxas de deposição muscular em machos castrados, machos não castrados e fêmeas. Com o intuito de aproveitar o efeito anabólico da testosterona, a imunocastração vem sendo cada vez mais difundida na suinocultura, levando machos imunocastrados a apresentarem desempenho e características de carcaça semelhantes a machos inteiros. De forma geral, o sexo parece desempenhar um importante papel na síntese proteica. Isso confere diferentes exigências de aminoácidos, em machos inteiros, fêmeas e machos castrados, devido às diferenças na deposição de proteína na carcaça.
\end{abstract}

Palavras chave: fêmeas, imunocastração, machos, síntese muscular

\section{Protein synthesis in pigs: how gilts, barrows and intact male respond to this process?}

\begin{abstract}
Muscle protein synthesis in pigs can be considered a key factor in promoting lean gain. However, this is a complex process depending on several enzymes, ribosomal proteins and may be affected by environmental factors, besides nutritional and hormonal. In this sense, sexual hormones may have anabolic action in protein synthesis, leading different rates of muscle deposition in barrows, intact males and gilts. Aiming to use the anabolic effect of testosterone, the immunocastration practice is being applied to pig production in many countries, allowing males to show the same growth performance and carcass traits as intact males. In this sense, sex plays an important role on protein synthesis, providing differences in the amino acids requirements, according to its condition (intact males, gilts and barrows) due to differences in carcass protein deposition.
\end{abstract}

Keywords: Gilts, immunocastration, barrows, muscle synthesis

\section{Síntesis proteica en porcinos: como las hembras, los machos castrados y los machos enteros responden a este proceso?}

RESUMEN. La síntesis de proteína muscular en porcinos es esencial para estimular la ganancia de carne magra. Sin embargo es un proceso complejo que involucra una cantidad innumerable de enzimas, proteínas ribosomales y puede ser influenciada por diferentes factores de orden ambiental, nutricional y hormonal. En este sentido, las hormonas sexuales pueden ejercer una acción anabólica en la síntesis de proteínas, conllevando a diferentes 
tasas de deposición muscular en machos castrados, machos enteros y hembras. Con el objetivo de emplear el efecto anabólico de la testosterona, la inmunocastración viene siendo cada vez más difundida en la porcicultura, llevando a los machos inmunocastrados a presentar desempeño y características de canal similares a los machos enteros. De manera general, el sexo parece desempeñar un importante papel en la síntesis de la proteína. Eso otorga diferentes exigencias de aminoácidos, en machos enteros, hembras y en machos castrados, debido a las diferencias en la deposición de proteína en la canal.

Palabras clave: hembras, inmunocastración, machos, síntesis de proteína muscular

\section{Introdução}

O rendimento de carcaça é o maior direcionador econômico do sistema de produção de carne suína, uma vez que a redução deste parâmetro afeta a rentabilidade de toda cadeia produtiva (Puls et al., 2014a, Puls et al., 2014b). Por essa razão, esta característica, juntamente com a deposição de carne magra, vem sendo cada vez mais abordadas em pesquisas nas áreas de genética (Schiavon et al., 2015), nutrição (Rickard et al., 2017) e ambiência (Berton et al., 2015), com o intuito de melhorar ainda mais estes parâmetros. Paralelamente, tem-se avaliado o sexo como fator que pode afetar as características de carcaça de suínos (Braña et al., 2013). Entretanto, vários processos metabólicos e fisiológicos antecedem a deposição de carne magra, essencialmente a síntese proteica. $\mathrm{O}$ metabolismo proteico celular, incluindo a síntese e degradação é essencial tanto para o crescimento hipertrófico como hiperplásico (Yang et al., 2008). No entanto, este processo é um dos mais complexos da bioquímica (Lehninger, 2006), orquestrado por inúmeros fatores de ordem nutricional, genética, hormonal, no qual neste último o sexo parece desempenhar um importante efeito.

Sabe-se que a utilização da proteína da dieta está associada com a capacidade do próprio suíno, ou com variabilidade entre animais (Brossard et al., 2009), em converter os aminoácidos (AA) ingeridos em proteína muscular. Além disso, os hormônios sexuais parecem contribuir para as diferenças no metabolismo muscular proteico, uma vez que as diferenças entre machos castrados, machos não castrados e fêmeas são claras tanto para as variáveis de desempenho (Font-i-Furnols et al., 2012, Morales et al., 2013, Puls et al., 2014b) quanto de rendimento de carcaça (Morales et al., 2013, Boler et al., 2014a, Puls et al., 2014a).

Neste contexto, esta revisão buscou abordar as diferenças entre sexos sobre a síntese proteica em suínos, e quais as ferramentas que vem sendo utilizadas para aproveitar o efeito do sexo na suinocultura.

\section{Mecanismos envolvidos na síntese proteica}

A síntese proteica possui um complexo processo de biossíntese no organismo dos animais (Figura 1). Para melhor entendimento, este processo divide-se em cinco etapas: (i) ativação de AA, (ii) iniciação, (iii) alongamento, (iv) terminação e reciclagem do ribossomo e (v) enovelamento e processamento pós-traducional.

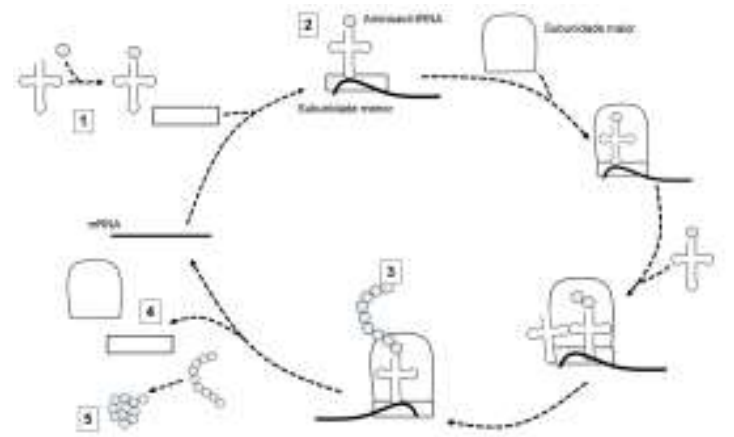

Figura 1. Visão geral da síntese proteica. 1, Os tRNAs são aminoacilados. 2, O início da tradução ocorre quando um mRNA e um tRNA aminoacilado ligam-se ao ribossomo. $\mathbf{3}$, durante o alongamento, o ribossomo se move ao longo do mRNA, combinando os tRNAs com cada códon e catalisando a formação da ligação peptídica. 4, A tradução termina em um códon de parada, e as subunidades ribossomais são liberadas e recicladas para um novo ciclo de síntese proteica. 5, Após ser sintetizada, a proteína precisa ser dobrada para atingir sua conformação ativa (adaptado de Lehninger (2006).

$\mathrm{Na}$ etapa de ativação de AA, que ocorre no citosol, cada um dos 20 AA é covalentemente ligado a um tRNA específico às custas de ATP e enzimas ativadoras dependentes de $\mathrm{Mg}^{+2}$ (aminoacil-tRNA-sintases), tornando o tRNA "carregado" (Monajjemi et al., 2014) sendo, em seguida, transferido para a extremidade 3' do tRNA cognato (Guo \& Schimmel, 2013).

A etapa subsequente refere-se à iniciação do processo de síntese proteica. O mRNA transcrito no núcleo da célula a partir da fita de DNA, contendo o código para a síntese do polipeptídeo, se liga à subunidade menor do ribossomo e ao aminoacil-tRNA iniciador; a subunidade maior do ribossomo se liga então para formar o complexo de iniciação (Rudorf \& Lipowsky, 2015). O 
aminoacil-tRNA estabelece um pareamento de bases com o códon AUG do mRNA, que especifica o AA metionina, sinalizando o início do processo, que é dependente de GTP e fatores de iniciação (Lehninger, 2006).

Além da metionina, ocorre a participação de uma proteína conhecida como mTOR (mammalian target of rapamycin), considerada um fator chave da síntese proteica no músculo esquelético, por regular numerosos componentes envolvidos na síntese proteica, incluindo fatores de iniciação e elongação (Wang \& Proud, 2006, You et al., 2015). Essa proteína quinase exerce um papel fundamental na regulação do crescimento muscular, e vários estudos evidenciaram a importância da mTOR como mediador central do metabolismo e crescimento (Yang et al., 2008). Sua atividade é regulada por hormônios e fatores de crescimento, além de ser dependente do status energético da célula e de AA que, na maioria das células, a leucina é o AA mediador (Kimball \& Jefferson, 2006, Manjarín et al., 2016).

$\mathrm{Na}$ fase de alongamento, o polipeptídeo formado é alongado pela adição de unidades sucessivas de AA ligadas covalentemente, oriundas da ligação entre o códon do mRNA e o anticódon do tRNA (Rudorf \& Lipowsky, 2015). Este processo requer fatores de alongamento, regulados pela mTOR (Wang \& Proud, 2006, You et al., 2015) e hidrólise de GTP.

A terminação e reciclagem do ribossomo é dada por um códon de parada no mRNA, fazendo com que o novo polipeptídeo seja liberado do ribossomo por ação de fatores de liberação, e o ribossomo é reciclado para uma nova síntese (Rudorf \& Lipowsky, 2015). Em condições normais, este processo ocorre com três códons de parada diferentes, UGA, UAA ou UAG (Fernández et al., 2013).

O novo polipeptídeo formado dobra-se em sua conformação tridimensional para ficar em sua forma ativa, sendo que, antes ou depois desse processo, pode sofrer processamento enzimático, como a remoção de um ou mais AA, adição de grupamentos acetil, fosforil, metil, carboxil (Lehninger, 2006). Esse processo, conhecido por modificação pós-traducional, tem grande influência sobre a natureza das proteínas, uma vez que pode regular sua atividade, localização, turnover e interação com outras proteínas e moléculas, como ácidos nucleicos, lipídeos e cofatores (Snider \& Omary, 2014).
De maneira geral, percebe-se que o processo de síntese proteica é extremamente dispendioso ao animal, visto que ocorre à custa de ATP e GTP. Estima-se que $70 \%$ do pool de ATP são consumidos durante o processo de tradução, considerada a atividade anabólica mais "onerosa" dentre os processos biossintéticos (Nilsen, 2015, Pontes et al., 2015). Além disso, a regulação da síntese proteica ocorre por meio de proteínas, fatores de iniciação e elongação, bem como hormônios da tireoide e do crescimento, insulina, glicocorticoides, andrógenos e estrógenos (Zhang et al., 2014, Lehninger, 2006).

\section{Relação entre a síntese proteica e o crescimento muscular}

A base metabólica para o crescimento do músculo esquelético consiste na relação entre as taxas de síntese e degradação da proteína muscular. A hipertrofia é possível apenas quando ocorre síntese líquida de proteína, ou seja, quando a síntese proteica excede a degradação (Tipton \& Wolfe, 2001).

$\mathrm{O}$ crescimento do tecido muscular em mamíferos pode ocorrer por hiperplasia (que cessa em curto período após o desenvolvimento embrionário) (Goldspink et al., 2001). E também por hipertrofia (predominantemente no período pós-natal) das fibras musculares, que leva ao aumento no número de núcleos de miofibrilas nas fibras musculares já existentes, a partir da proliferação e diferenciação das células satélites (Moss \& Leblond, 1971).

Quando a célula satélite é ativada, os núcleos derivados desta célula iniciam o processo de síntese de proteínas musculares específicas, aumentando o volume das fibras musculares devido à formação de novos sarcômeros (Silva \& Carvalho, 2007). Dessa forma, a hipertrofia ocorre devido a uma cascata de eventos, como ativação muscular e síntese de proteína, devido ao aumento dos processos de transcrição e tradução (Spiering et al., 2008).

De maneira geral, vários fatores podem afetar a resposta hipertrófica, como fatores nutricionais e hormonais. Com relação aos fatores nutricionais, sabe-se que os AA são necessários como precursores para a síntese proteica (Garlick \& Grant, 1988), sendo que o aumento da disponibilidade de AA exógenos demonstrou elevar a síntese proteica no músculo (Svanberg et al., 1996, Biolo et al., 1997). 
Diversas evidências têm apontado que a via de sinalização da mTOR é a maior reguladora da síntese proteica muscular. A eficácia da tradução proteica se dá principalmente no processo de iniciação, onde ocorre a ligação dos fatores de tradução ao mRNA. Essas alterações levam ao balanço proteico positivo e, consequentemente, à hipertrofia (Terzis et al., 2010). Diversos estudos demonstraram que os AA de cadeia ramificada, em particular a leucina são os mais potentes, devido ao seu potencial anabólico, estimulando o início do processo de tradução proteica e da sinalização celular via cascata da mTOR (Dreyer et al., 2006, Wang \& Proud, 2006).

Com relação aos fatores hormonais, estudos vêm demonstrando que a testosterona é responsável pelo aumento da síntese proteica, o que confere a suínos machos não castrados melhor deposição de carne magra que machos castrados (Font-i-Furnols et al., 2012, Morales et al., 2013, Puls et al., 2014a, Puls et al., 2014b).

\section{Papel dos hormônios sexuais no metabolismo proteico}

A testosterona e o estrogênio são hormônios sexuais esteroides, sintetizados nos testículos e ovários, respectivamente, a partir do colesterol, sendo deslocados para suas células-alvo através da corrente sanguínea, ligados a proteínas carreadoras (Lehninger, 2006). Estes hormônios atuam por meio de receptores nucleares (Figura 2), alterando o nível de expressão de genes específicos, e afetam o desenvolvimento e o comportamento sexual.

Esse tipo de atuação, em nível nuclear, confere aos hormônios esteroides respostas mais lentas, sendo necessárias horas ou dias para que esses reguladores exerçam completamente seus efeitos (Lehninger, 2006), pois atuam em nível de mRNA, alterando a expressão gênica (Ing, 2005). A partir do conhecimento do modo de ação dos hormônios esteroides, pode-se inferir que, por alterarem a expressão gênica de proteínas específicas, podem afetar a síntese proteica.

A maior parte da testosterona, que se fixa aos tecidos, é convertida dentro das células a dihidrotestosterona Figura 3; Guyton \& Hall (2011). Algumas ações da testosterona são dependentes dessa conversão (Borst \& Yarrow, 2015).
A testosterona está envolvida no aumento da matriz óssea, retenção de cálcio e aumento do metabolismo basal (Guyton \& Hall, 2011), sendo suas concentrações normalmente $10-15$ vezes maiores em machos que em fêmeas (Tipton \& Wolfe, 2001). Devido seu grande efeito na musculatura, machos inteiros frequentemente apresentam maior deposição proteica muscular que machos castrados (Millet et al., 2011). Já o estrogênio causa um pequeno aumento na proteína corporal total, resultado principalmente do efeito promotor de crescimento que o estrogênio exerce nos órgãos sexuais, ossos e alguns outros tecidos do corpo, entretanto seus efeitos são menos evidentes que os causado pela testosterona em machos (Guyton \& Hall, 2011).

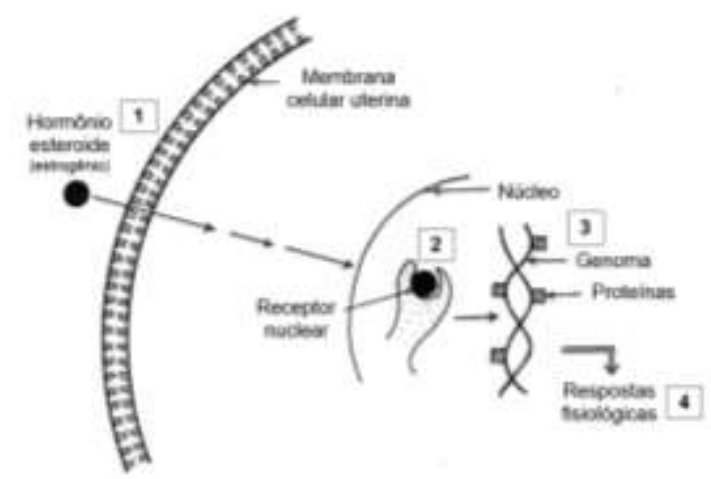

Figura 2. Mecanismo pelo qual os hormônios esteroides regulam a expressão gênica. 1, Os hormônios (estrogênio, por exemplo), transportados até o tecido-alvo por proteínas transportadoras séricas, difundem-se pela membrana plasmática. 2, O hormônio liga-se a receptores proteicos específicos no núcleo, alterando a conformação do receptor. O complexo "hormônio-receptor" liga-se a regiões reguladoras específicas chamadas de elementos de resposta a hormônio, no DNA adjacente de genes específicos. 3, o complexo interage com outras proteínas, regulando assim a transcrição dos genes adjacentes, aumentando ou diminuindo a taxa de formação do mRNA. 4, Os níveis alterados do produto gênico regulado pelo hormônio produzem respostas fisiológicas que, no caso do estrogênio, serão crescimento e diferenciação tecidual (Adaptado de Lehninger (2006)

Dessa forma, a testosterona parece contribuir de forma significativa com o aumento da massa muscular, devido ao aumento da síntese proteica e redução na degradação da proteína muscular, enquanto que a contribuição dos hormônios ovarianos parece ser menos efetiva. Isso evidencia que machos inteiros devem apresentar melhor deposição proteica que fêmeas que, por sua vez, serão melhores que machos castrados (Boler et al., 2014b, Puls et al., 2014a, Puls et al., 2014b, Van den Broeke et al., 2016). 


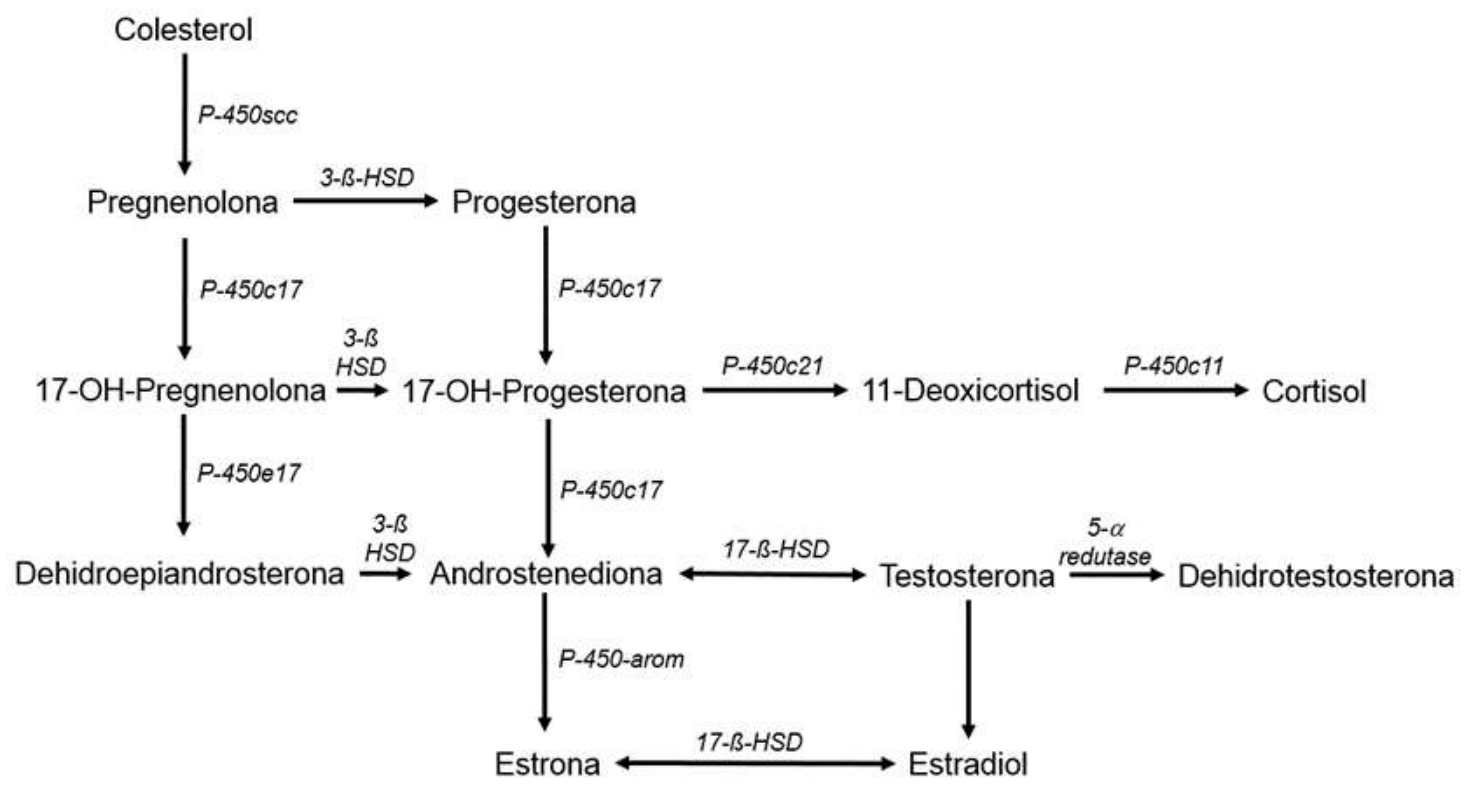

Figura 3. Hormônios esteroides derivados do colesterol. A testosterona pode agir diretamente nos receptores andrógenos ou indiretamente seguindo a conversão a estradiol ou di-hidrotestosterona (Adaptado a partir de Lehninger (2006) e Borst \& Yarrow (2015).

Devido às diferenças em termos de deposição proteica em machos inteiros, machos castrados e fêmeas, algumas pesquisas foram conduzidas avaliando as possibilidades de se explorar a maior síntese proteica em suínos, de acordo com o sexo. Entre os temas mais abordados destaca-se a imunocastração (Fàbrega et al., 2010, Batorek et al., 2012a, Puls et al., 2014a, Puls et al., 2014b, Van den Broeke et al., 2016), que visa o aproveitamento dos efeitos anabólicos da testosterona.

\section{Alternativas para explorar a síntese proteica em suínos machos}

A imunocastração é uma alternativa à castração cirúrgica, para controlar o odor sexual característico de machos inteiros (escatol e androsterona). A grande vantagem dessa técnica é a possibilidade de os suínos machos manterem as características naturais de crescimento, favorecendo o potencial genético dos animais.

A imunocastração consiste em duas doses de uma vacina, sem atividade hormonal ou farmacológica, que estimula o sistema imune do suíno a produzir anticorpos contra seu GnRF natural (Pinna et al., 2015). O GnRF é o hormônio que sinaliza a hipófise para sintetizar o hormônio luteinizante (LH) e o hormônio folículo estimulante (FSH), os quais controlam a função testicular. A partir desta vacina, os compostos do odor do macho inteiro, já presentes no suíno, são rapidamente metabolizados e eliminados do organismo, uma vez que o bloqueio da síntese de LH e FSH interrompe a produção de esteroides testiculares.

A grande vantagem da imunocastração para suínos é o aproveitamento dos efeitos anabólicos integrais da testosterona, uma vez que os animais são machos inteiros até receberem a segunda dose da vacina (Millet et al., 2011). Este fato foi confirmado em uma série de estudos, que demonstraram pouca ou nenhuma diferença no ganho médio e eficiência alimentar entre machos imunocastrados e machos inteiros, entre a primeira e segunda dose (Fàbrega et al., 2010, Batorek et al., 2012a, Morales et al., 2013).

Uma vez que a taxa de síntese proteica é influenciada pelos hormônios sexuais, o que confere diferentes taxas de crescimento muscular espera-se que os parâmetros de desempenho e características de carcaça em suínos variem de acordo com o sexo e com a utilização da imunocastração. As diferentes exigências para deposição proteica, bem como diferentes valores de deposição de proteína entre os sexos (NRC, 2012, Rostagno et al., 2017) dão suporte à esta indicação.

Essas diferenças podem ser observadas no desempenho e características de carcaça (Tabela 1) de suínos. Vários estudos avaliaram a taxa de crescimento, consumo de ração e eficiência alimentar em machos castrados, machos não castrados e fêmeas. Devido às diferenças entre 
sexos, os suínos responderiam melhor à dieta se produzidos em sistema de manejo alimentar separado por sexo, com intuito de maximizar o crescimento.

De acordo com dados encontrados na literatura, suínos machos inteiros apresentam maior potencial de deposição proteica que os outros sexos, e isso se reflete em melhor desempenho e maior exigência de lisina digestível (NRC, 2012, Rostagno et al., 2017), Já as fêmeas possuem melhores índices que machos castrados.

Tabela 1. Desempenho e características de carcaça de suínos de acordo com o gênero.

\begin{tabular}{|c|c|c|c|c|c|c|c|c|}
\hline \multirow[b]{2}{*}{ Variáveis } & \multirow[b]{2}{*}{$\begin{array}{c}\mathrm{N}^{\circ} \\
\text { animais }\end{array}$} & \multirow[b]{2}{*}{$\begin{array}{l}\text { Peso, } \\
\text { kg }\end{array}$} & \multirow[b]{2}{*}{ Alojamento } & \multirow[b]{2}{*}{ Alimentação } & \multicolumn{4}{|c|}{ Gênero } \\
\hline & & & & & $\begin{array}{l}\text { Machos } \\
\text { castrados }\end{array}$ & $\begin{array}{l}\text { Machos } \\
\text { inteiros }\end{array}$ & $\begin{array}{c}\text { Machos } \\
\text { imuno } \\
\text { castrados }\end{array}$ & Fêmeas \\
\hline \multicolumn{9}{|c|}{ Ganho de peso diário, $\mathrm{kg} / \mathrm{d}$} \\
\hline Puls et al. (2014b) & 192 & $67-133$ & Baia (4) & Ad libitum & 1,02 & 1,06 & 1,15 & 0,954 \\
\hline Puls et al. (2014a) & 180 & $70-137$ & Baia (4) & Ad libitum & 1,08 & 1,25 & - & 1,03 \\
\hline Morales et al. (2013) & 240 & $42-125$ & Baia (8) & Ad libitum & 1,03 & 1,18 & - & 1,00 \\
\hline$\frac{\text { Font-i-Furnols et al. }}{(2012)}$ & 75 & $32-140$ & Baia (9) & Ad libitum & 0,770 & 0,910 & - & 0,770 \\
\hline Batorek et al. (2012b) & 64 & $28-110$ & Individual & Ad libitum & 0,960 & 0,930 & 0,880 & - \\
\hline Batorek et al. (2012a) & 64 & $28-110$ & Individual & Ad libitum & 0,940 & 1,13 & 0,960 & - \\
\hline Morales et al. (2011) & 360 & $20-127$ & Baia (10) & Ad libitum & 0,930 & 1,05 & - & 0,930 \\
\hline Fàbrega et al. (2010) & 150 & $28-115$ & Baia (15) & Ad libitum & 0,930 & 0,840 & 0,840 & 0,870 \\
\hline \multicolumn{9}{|l|}{ Eficiência alimentar } \\
\hline$\underline{\text { Puls et al. (2014b) }}$ & 192 & $67-133$ & Baia (4) & Ad libitum & 0,335 & 0,397 & 0,371 & 0,347 \\
\hline Puls et al. (2014a) & 180 & $70-137$ & Baia (4) & Ad libitum & 0,322 & 0,371 & - & 0,358 \\
\hline Morales et al. (2011) & 240 & $42-125$ & Baia (8) & Ad libitum & 0,300 & 0,350 & - & 0,320 \\
\hline Batorek et al., 2012b) & 64 & $28-110$ & Individual & Ad libitum & 0,420 & 0,450 & 0,440 & - \\
\hline Batorek et al. (2012a) & 64 & $28-110$ & Individual & Ad libitum & 0,260 & 0,320 & 0,300 & \\
\hline Morales et al. (2011) & 360 & $20-127$ & Baia (10) & Ad libitum & 0,290 & 0,320 & - & 0,300 \\
\hline \multicolumn{9}{|c|}{ Rendimento de carcaça, \% } \\
\hline Puls et al. (2014a) & 180 & $70-137$ & Baia (4) & Ad libitum & 75,0 & 72,8 & - & 74,6 \\
\hline Boler et al. (2014a) & 180 & 130 & Baia (4) & Ad libitum & 78,7 & 77,3 & 77,4 & 78,5 \\
\hline Morales et al. (2013) & 240 & $42-125$ & Baia (8) & Ad libitum & 78,1 & 76,6 & - & 78,8 \\
\hline Boler et al. (2012) & 156 & - & Baia (25) & Ad libitum & 74,5 & 71,8 & - & - \\
\hline Batorek et al. (2012a) & 64 & $28-110$ & Individual & Ad libitum & 79,6 & 77,3 & 78,4 & - \\
\hline Morales et al. (2011) & 360 & $20-127$ & Baia (10) & Ad libitum & 78,7 & 77,2 & - & 79,1 \\
\hline \multicolumn{9}{|c|}{ Espessura de toucinho, $\mathbf{m m}$} \\
\hline Overholt et al. (2016) & - & - & - & - & 29,9 & - & - & 39,2 \\
\hline Boler et al. (2014b) & 180 & 130 & Baia (4) & Ad libitum & 25,2 & 24,3 & 18,2 & 21,1 \\
\hline Morales et al. (2013) & 240 & $42-125$ & Baia (8) & Ad libitum & 28,7 & 26,1 & - & 26,6 \\
\hline Boler et al. (2012) & 156 & - & Baia (25) & Ad libitum & 17,7 & 16,3 & - & \\
\hline Batorek et al. (2012a) & 64 & $28-110$ & Individual & Ad libitum & 14,8 & 12,9 & 9,80 & - \\
\hline Morales et al. (2011) & 360 & $20-127$ & Baia (10) & Ad libitum & 26,4 & 23,3 & - & 24,3 \\
\hline
\end{tabular}

\section{Tendências futuras em pesquisas sobre deposição proteica}

A base metabólica para o aumento da musculatura requer um balanço líquido positivo da proteína muscular, ou seja, a síntese proteica muscular deve exceder a degradação proteica. Tendo em consideração o efeito anabólico dos hormônios sexuais, principalmente da testosterona, explica-se porque machos inteiros apresentam maior deposição muscular que fêmeas e machos castrados. Em humanos, trabalhos evidenciaram que a testosterona aumenta a taxa de síntese proteica muscular (Wang et al., 2012). Utilizando a técnica de isótopos estáveis, Smith et al. (2012) observaram que homens apresentam 
taxa de síntese proteica muscular até $30 \%$ mais elevada que mulheres.

O uso de isótopos estáveis, em estudos de deposição proteica, parece ser interessante para compreender a cinética do metabolismo das proteínas, uma vez que estes participam das rotas metabólicas em reações de síntese e degradação dentro de um organismo, e podem ser rastreados devido à sua estabilidade nuclear (Sakomura \& Rostagno, 2007). Em suínos, esta técnica já foi utilizada em diversos estudos. Em 1992 foi avaliado o metabolismo do nitrogênio e o turnover proteico corporal utilizando isótopos estáveis (Tomas et al., 1992). Mais recentemente, Kampman-van de Hoek et al. (2016) utilizaram isótopos estáveis para determinar a utilização de AA e retenção de nitrogênio corporal em animais em crescimento e terminação. Da mesma forma, Zhang et al. (2016) utilizaram esta técnica para compreender o turnover proteico corporal em suínos em terminação. Entretanto, até o momento, não se tem o conhecimento do emprego desta técnica para avaliar o metabolismo proteico em diferentes sexos, como já ocorreu com humanos (Tipton \& Wolfe, 2001, Borst \& Yarrow, 2015). Portanto, este parece ser um tópico interessante a ser abordado em estudos futuros, para a melhor compreensão do metabolismo proteico corporal em machos castrados, machos inteiros e fêmeas.

\section{Considerações finais}

As diferenças observadas para o desempenho entre suínos machos inteiros, machos castrados e fêmeas são reflexo das diferenças no metabolismo proteico, especialmente o muscular. $\mathrm{O}$ sexo desempenha um importante papel no metabolismo, conferindo diferentes taxas de utilização dos nutrientes. Muito do que se sabe a sobre o papel dos hormônios esteroides é que eles aumentam a massa muscular, mas ainda parece que os mecanismos que regulam a ação fisiológica e molecular dos hormônios esteroides, e sua função na regulação da massa muscular no músculo esquelético, precisam ser mais bem elucidados. Isso exigirá futuras análises científicas para entender melhor a natureza deste processo.

\section{Referências Bibliográficas}

Batorek, N., Čandek-Potokar, M., Bonneau, M. \& Van Milgen, J. 2012a. Meta-analysis of the effect of immunocastration on production performance, reproductive organs and boar taint compounds in pigs. Animal, 6, 13301338.
Batorek, N., Škrlep, M., Prunier, A., Louveau, I., Noblet, J., Bonneau, M. \& Čandek-Potokar, M. $2012 \mathrm{~b}$. Effect of feed restriction on hormones, performance, carcass traits, and meat quality in immunocastrated pigs. Journal of Animal Science, 90, 4593-4603.

Berton, M. P., Cássia Dourado, R., Lima, F. B. F., Rodrigues, A. B. B., Ferrari, F. B., Carmo Vieira, L. D., Souza, P. A. \& Borba, H. 2015. Growing-finishing performance and carcass yield of pigs reared in a climate-controlled and uncontrolled environment. International Journal of Biometeorology, 59, 955-960.

Biolo, G., Tipton, K. D., Klein, S. \& Wolfe, R. R. 1997. An abundant supply of amino acids enhances the metabolic effect of exercise on muscle protein. American Journal of Physiology-Endocrinology And Metabolism, 273, E122-E129.

Boler, D. D., Killefer, J., Meeuwse, D. M., King, V. L., McKeith, F. K. \& Dilger, A. C. 2012. Effects of slaughter time post-second injection on carcass cutting yields and bacon characteristics of immunologically castrated male pigs. Journal of Animal Science, 90, 334344.

Boler, D. D., McKeith, F. K., Puls, C. L., Ellis, M., Wood-Follis, S. L., Miller, R. W., Vanimisetti, H. B., Moseley, W. M., Schroeder, A. L. \& Dilger, A. C. 2014a. Effects of generic ractopamine (Engain) on the growth performance, carcass characteristics, meat quality, and cutability of finishing barrows and gilts. The Professional Animal Scientist, 30, 625-636.

Boler, D. D., Puls, C. L., Clark, D. L., Ellis, M., Schroeder, A. L., Matzat, P. D., Killefer, J., McKeith, F. K. \& Dilger, A. C. 2014b. Effects of immunological castration (Improvest) on changes in dressing percentage and carcass characteristics of finishing pigs. Journal of Animal Science, 92, 359-368.

Borst, S. E. \& Yarrow, J. F. 2015. Injection of testosterone may be safer and more effective than transdermal administration for combating loss of muscle and bone in older men. American Journal of PhysiologyEndocrinology and Metabolism, 308, E1035E1042.

Braña, D. V., Rojo-Gómez, G. A., Ellis, M. \& Cuaron, J. A. 2013. Effect of gender (gilt and surgically and immunocastrated male) and ractopamine hydrochloride supplementation 
on growth performance, carcass, and pork quality characteristics of finishing pigs under commercial conditions. Journal of Animal Science, 91, 5894-5904.

Brossard, L., Dourmad, J. Y., Rivest, J. \& Van Milgen, J. 2009. Modelling the variation in performance of a population of growing pig as affected by lysine supply and feeding strategy. Animal, 3, 1114-1123.

Dreyer, H. C., Fujita, S., Cadenas, J. G., Chinkes, D. L., Volpi, E. \& Rasmussen, B. B. 2006. Resistance exercise increases AMPK activity and reduces 4E-BP1 phosphorylation and protein synthesis in human skeletal muscle. The Journal of Physiology, 576, 613-624.

Fàbrega, E., Velarde, A., Cros, J., Gispert, M., Suárez, P., Tibau, J. \& Soler, J. 2010. Effect of vaccination against gonadotrophin-releasing hormone, using Improvac ${ }^{\circledR}$, on growth performance, body composition, behaviour and acute phase proteins. Livestock Science, 132, 53-59.

Fernández, I. S., Ng, C. L., Kelley, A. C., Wu, G., Yu, Y.-T. \& Ramakrishnan, V. 2013. Unusual base pairing during the decoding of a stop codon by the ribosome. Nature, 500, 107-110.

Font-i-Furnols, M., Gispert, M., Soler, J., Diaz, M., Garcia-Regueiro, J. A., Diaz, I. \& Pearce, M. C. 2012. Effect of vaccination against gonadotrophin-releasing factor on growth performance, carcass, meat and fat quality of male Duroc pigs for dry-cured ham production. Meat Science, 91, 148-154.

Garlick, P. J. \& Grant, I. 1988. Amino acid infusion increases the sensitivity of muscle protein synthesis in vivo to insulin. Effect of branched-chain amino acids. Biochemical Journal, 254, 579-584.

Goldspink, G., Wilkes, D. \& Ennion, S. 2001. Myosin expression during ontogeny, posthatching growth, and adaptation. Fish Physiology: Muscle Development and Growth, 18, 43-72.

Guo, M. \& Schimmel, P. 2013. Essential nontranslational functions of tRNA synthetases. Nature Chemical Biology, 9, 145153.

Guyton, A. C. \& Hall, J. E. 2011. Tratado de fisiologia médica. Elsevier Brasil.

Ing, N. H. 2005. Steroid hormones regulate gene expression posttranscriptionally by altering the stabilities of messenger RNAs. Biology of Reproduction, 72, 1290-1296.

Kampman-van de Hoek, E., Jansman, A. J., van den Borne, J. J., van der Peet-Schwering, C. M., van Beers-Schreurs, H. \& Gerrits, W. J. 2016. Dietary amino acid deficiency reduces the utilization of amino acids for growth in growing pigs after a period of poor health. The Journal of Nutrition, 146, 51-58.

Kimball, S. R. \& Jefferson, L. S. 2006. Signaling pathways and molecular mechanisms through which branched-chain amino acids mediate translational control of protein synthesis. The Journal of Nutrition, 136, 227S-231S.

Lehninger, N. D. L. 2006. Principios de bioquímica. São Paulo.

Manjarín, R., Columbus, D. A., Suryawan, A., Nguyen, H. V., Hernandez-García, A. D., Hoang, N.-M., Fiorotto, M. L. \& Davis, T. 2016. Leucine supplementation of a chronically restricted protein and energy diet enhances mTOR pathway activation but not muscle protein synthesis in neonatal pigs. Amino Acids, 48, 257-267.

Millet, S., Gielkens, K., Brabander, D. \& Janssens, G. P. J. 2011. Considerations on the performance of immunocastrated male pigs. Animal, 5, 1119-1123.

Monajjemi, M., Wayne, R. \& Boggs, J. E. 2014. NMR contour maps as a new parameter of carboxyl's $\mathrm{OH}$ groups in amino acids recognition: A reason of tRNA-amino acid conjugation. Chemical Physics, 433, 1-11.

Morales, J. I., Cámara, L., Berrocoso, J. D., López, J. P., Mateos, G. G. \& Serrano, M. P. 2011. Influence of sex and castration on growth performance and carcass quality of crossbred pigs from 2 Large White sire lines. Journal of Animal Science, 89, 3481-3489.

Morales, J. I., Serrano, M. P., Cámara, L., Berrocoso, J. D., López, J. P. \& Mateos, G. G. 2013. Growth performance and carcass quality of immunocastrated and surgically castrated pigs from crossbreds from Duroc and Pietrain sires. Journal of Animal Science, 91, 39553964.

Moss, F. P. \& Leblond, C. P. 1971. Satellite cells as the source of nuclei in muscles of growing rats. The Anatomical Record, 170, 421-435.

Nilsen, T. W. 2015. Twenty years of RNA: then and now. $R N A, 21,471-473$. 
NRC. 2012. Nutrient Requirements of Swine, 7th rev. edn. Natl. Acad. Press, Washington, DC., Washington.

Overholt, M. F., Arkfeld, E. K., Mohrhauser, D. A., King, D. A., Wheeler, T. L., Dilger, A. C., Shackelford, S. D. \& Boler, D. D. 2016. Comparison of variability in pork carcass composition and quality between barrows and gilts. Journal of Animal Science, 94, 44154426.

Pinna, A., Schivazappa, C., Virgili, R. \& Parolari, G. 2015. Effect of vaccination against gonadotropin-releasing hormone $(\mathrm{GnRH})$ in heavy male pigs for Italian typical dry-cured ham production. Meat Science, 110, 153-159.

Pontes, M. H., Sevostyanova, A. \& Groisman, E. A. 2015. When too much ATP is bad for protein synthesis. Journal of Molecular Biology, 427, 2586-2594.

Puls, C. L., Ellis, M., McKeith, F. K., Gaines, A. M. \& Schroeder, A. L. 2014a. Effects of ractopamine on growth performance and carcass characteristics of immunologically and physically castrated barrows and gilts. Journal of Animal Science, 92, 4725-4732.

Puls, C. L., Rojo, A., Ellis, M., Boler, D. D., McKeith, F. K., Killefer, J., Gaines, A. M., Matzat, P. D. \& Schroeder, A. L. 2014 b. Growth performance of immunologically castrated (with Improvest) barrows (with or without ractopamine) compared to gilt, physically castrated barrow, and intact male pigs. Journal of Animal Science, 92, 22892295.

Rickard, J. W., Allee, G. L., Rincker, P. J., Gooding, J. P., Acheson, R., McKenna, D. R. \& Carr, S. N. 2017. Impact of ractopamine hydrochloride (Paylean ${ }^{\circledR}$ ) on performance of heavy finishing pigs using a 3-cut marketing strategy. Journal of Animal Science, 95, 98-98.

Rostagno, H. S., Albino, L. F. T., Donzele, J. L., Gomes, P. C., Oliveira, R., Lopes, D. C., Ferreira, A. S., Barreto, S. \& Euclides, R. F. 2017. Composição de alimentos e exigências nutricionais, 3 edn. Universidade Federal de Viçosa, Viçosa.

Rudorf, S. \& Lipowsky, R. 2015. Protein synthesis in E. coli: dependence of codon-specific elongation on tRNA concentration and codon usage. PloS one, 10, e0134994.

Sakomura, N. K. \& Rostagno, H. S. 2007. Métodos de pesquisa em nutrição de monogástricos. FUNEP, Jaboticabal.
Schiavon, S., Carraro, L., Dalla Bona, M., Cesaro, G., Carnier, P., Tagliapietra, F., Sturaro, E., Galassi, G., Malagutti, L. \& Trevisi, E. 2015. Growth performance, and carcass and raw ham quality of crossbred heavy pigs from four genetic groups fed low protein diets for drycured ham production. Animal Feed Science and Technology, 208, 170-181.

Silva, M. D. P. \& Carvalho, R. F. 2007. Mecanismos celulares e moleculares que controlam o desenvolvimento e o crescimento muscular. Revista Brasileira de Zootecnia, 36, 21-31.

Smith, G.I.; Reeds, D.N.; Hall, A.M., Chambers, K. T., Finck, B. N. \& Mittendorfer, B. 2012 Sexually dimorphic effect of aging on skeletal muscle protein synthesis. Biology of Sex Diferences, 3, .1-11.

Snider, N. T. \& Omary, M. B. 2014. Posttranslational modifications of intermediate filament proteins: mechanisms and functions. Nature Reviews Molecular Cell Biology, 15, 163-177.

Spiering, B. A., Kraemer, W. J., Anderson, J. M., Armstrong, L. E., Nindl, B. C., Volek, J. S. \& Maresh, C. M. 2008. Resistance exercise biology. Sports Medicine, 38, 527-540.

Svanberg, E., Moller-Loswick, A. C., Matthews, D. E., Korner, U., Andersson, M. \& Lundholm, K. 1996. Effects of amino acids on synthesis and degradation of skeletal muscle proteins in humans. American Journal of PhysiologyEndocrinology And Metabolism, 271, E718E724.

Terzis, G., Spengos, K., Mascher, H., Georgiadis, G., Manta, P. \& Blomstrand, E. 2010. The degree of p70S6k and S6 phosphorylation in human skeletal muscle in response to resistance exercise depends on the training volume. European Journal of Applied Physiology, 110, 835-843.

Tipton, K. D. \& Wolfe, R. R. 2001. Exercise, protein metabolism, and muscle growth. International Journal of Sport Nutrition and Exercise Metabolism, 11, 109-132.

Tomas, F. M., Campbell, R. G., King, R. H., Johnson, R. J., Chandler, C. S. \& Taverner, M. R. 1992. Growth hormone increases wholebody protein turnover in growing pigs. Journal of Animal Science, 70, 3138-3143.

Van den Broeke, A., Leen, F., Aluwé, M., Ampe, B., Van Meensel, J. \& Millet, S. 2016. The effect of GnRH vaccination on performance, 
carcass, and meat quality and hormonal regulation in boars, barrows, and gilts. Journal of Animal Science, 94, 2811-2820.

Wang, X. \& Proud, C. G. 2006. The mTOR pathway in the control of protein synthesis. Physiology, 21, 362-369.

Wang, X., Smith, G. I., Patterson, B. W., Reeds, D. N., Kampelman, J., Magkos, F. \& Mittendorfer, B. 2012. Testosterone increases the muscle protein synthesis rate but does not affect very-low-density lipoprotein metabolism in obese premenopausal women. American Journal of Physiology Endocrinology and Metabolism, 302, 740-746.

Yang, X., Yang, C., Farberman, A., Rideout, T. C., De Lange, C. F. M., France, J. \& Fan, M. Z. 2008. The mammalian target of rapamycinsignaling pathway in regulating metabolism and growth. Journal of Animal Science, 86, E36-E50.

You, J.-S., Anderson, G. B., Dooley, M. S. \& Hornberger, T. A. 2015. The role of mTOR signaling in the regulation of protein synthesis and muscle mass during immobilization in mice. Disease Models \& Mechanisms, 8, 10591069.

Zhang, S., Chu, L., Qiao, S., Mao, X. \& Zeng, X. 2016. Effects of dietary leucine supplementation in low crude protein diets on performance, nitrogen balance, whole-body protein turnover, carcass characteristics and meat quality of finishing pigs. Animal Science Journal, 87, 911-920.

Zhang, Y., Nicholatos, J., Dreier, J. R., Ricoult, S. J. H., Widenmaier, S. B., Hotamisligil, G. S., Kwiatkowski, D. J. \& Manning, B. D. 2014. Coordinated regulation of protein synthesis and degradation by mTORC1. Nature, 513, 440-443.

\section{Article History:}

Received 11 September 2017

Accepted 9 October 2017

Available online 25 November 2017

License information: This is an open-access article distributed under the terms of the Creative Commons Attribution License 4.0, which permits unrestricted use, distribution, and reproduction in any medium, provided the original work is properly cited. 